\title{
Metastasis of breast cancer to bladder
}

\author{
Asma Hadhri ${ }^{{ }^{*}}$ D, Rim Abidi ${ }^{1}$, Najet Mahjoub ${ }^{4}$, Alia Mousli ${ }^{1}$, Khalil Mahjoubi ${ }^{1}$, Nadia Boujelbene ${ }^{2,3}$ and \\ Chiraz Nasr ${ }^{1}$
}

\begin{abstract}
Background: Breast cancer is the leading cause of cancer death in women, and most breast cancer related deaths are due to metastasis. Urinary bladder metastasis from breast cancer is rarely reported in the literature.

Case presentation: We report a case of a 77-year-old female with history of left breast cancer, who presented a thickening of the bladder wall at pelvic ultrasound. Biopsy confirmed that the origin was lobular carcinoma of breast origin. The patient received chemotherapy, but the clinical course of the patient was very aggressive and she died one year later.

Conclusion: Bladder metastasis from breast cancer is rare, but the literature reveals an increase in such occurrence over the last few years. Pathologic diagnosis relies on immunohistochemical studies. Chemotherapy and hormonal treatment represent the standard therapy, with radiotherapy being used only to control bladder bleeding. The prognosis is usually poor.
\end{abstract}

Keywords: Breast cancer, Bladder metastasis, Prognosis, Case report

\section{Background}

Background. In Tunisia as in the rest of the world, breast cancer is the most common cancer in women. A Tunisian study published in 2017 found that breast cancer incidence rate among women was estimated to $50.17 / 100000$ persons years [1].

Breast cancer usually causes metastases in the lungs, liver, bone, and brain.

Given the mortality associated with metastatic disease, it is important for physicians to be aware of potential rare sites of metastasis such as bladder [2].

We report a case of a 77-year-old patient who developed a bladder metastasis from breast cancer.

\section{Case presentation}

We report a case of a 77-year-old female with history of breast cancer, metastatic to bone initially and later to the bladder. Her family history is not significant and she is not known to have medical problems.

\footnotetext{
*Correspondence: Asma.hadhri@gmail.com

${ }^{1}$ Radiotherapy Unit, Salah Azaiez Institute of Cancer, Boulevard du 9 avri

1938 Bab Saâdoun, 1007 Tunis, Tunisia

Full list of author information is available at the end of the article
}

The patient was diagnosed with left breast cancer in 1992 and treated with left mastectomy, left axillary nodal dissection. Histopathology was invasive lobular carcinoma, Scarff-Bloom-Richardson grade 3, negative hormone receptor, and two axillary lymph node metastases. She received 6 cycles of chemotherapy (fluorouracil 5FU, epirubicin, and cyclophosphamide), and locoregional radiation therapy at the dose of $50 \mathrm{~Gy}$. After 2 years, she underwent right mastectomy for ductal carcinoma in situ (DCIS) without further adjuvant treatment.

She did not receive treatment for 13 years. In 2007, during routine follow-up, a pelvic ultrasound revealed an irregular thickening of the bladder wall. The patient was otherwise asymptomatic. Cystoscopy and biopsy showed malignant epithelial cells involving the lamina propria of the bladder. The immunohistochemical staining pattern was consistent with metastatic lobular breast carcinoma, which was cytokeratine 7 and GATA3 positive. (Figs. 1 and 2).

Bone scan showed extensive bone metastases. The patient received 6 cycles of chemotherapy (taxotere) with zoledronic acid. Therapy changed to single agent capecitabine because of disease progression after 6 months. 
Computed tomography body scan showed extensive bone progression and increased bladder tumor size.

The clinical course of the patient was very aggressive, and she died one year after bladder metastasis diagnosis.

\section{Discussion}

Breast cancer is frequent and occurs in one in four women [2]. Despite advances in therapy and detection, metastasis of breast cancer is the main cause of death in breast cancer patients [3].

Breast cancer metastasis to brain, liver, lungs, bone, and lymph nodes is the most common [4]. However, the urinary bladder represents a rather uncommon site of breast cancer metastasis [5].

The main mechanism for the occurrence of bladder metastasis is the expansion from adjacent pelvic cancer (prostate or cervical cancer). Cancers in distant organs usually don't generate metastases to the bladder; some

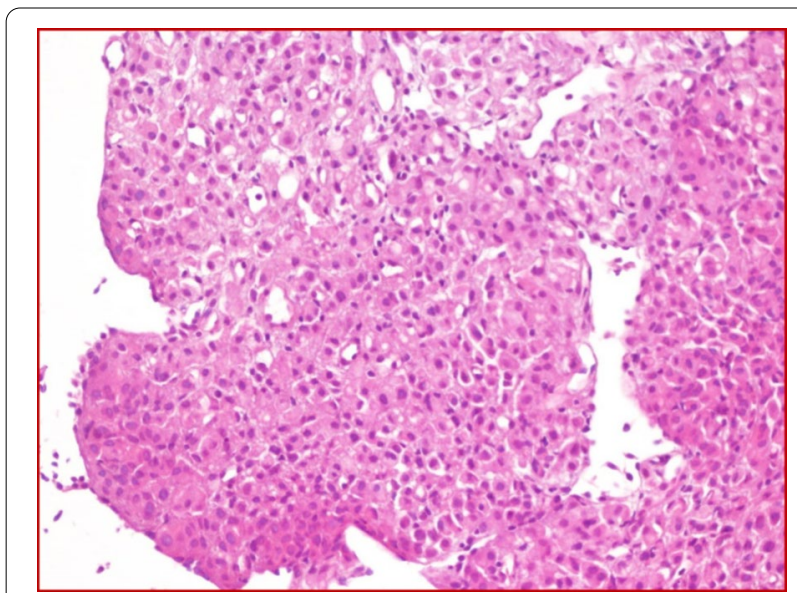

Fig. 1 Mucosal lamina propria of bladder invaded by poorly differentiated adenocarcinoma $(H E \times 200)$ cases have been occasionally described with the stomach, lung, and skin cancer [6].

Only 65 cases in the literature reported bladder metastases cases from breast carcinoma [2], usually found during biopsies $[6,7]$.

The histological type of cancer may determine the pattern of metastasis in breast cancer. Although ductal carcinoma is the common histological subtype with $90 \%$ of cases in the primary breast cancer, it was found that invasive lobular carcinoma was the main histological subtype associated with bladder metastases $[2,8,9]$.

Infiltrating lobular carcinoma (ILC) represents $8 \%$ to $14 \%$ of cases [2] and tends to spread to gastrointestinal tract, genitourinary tract, peritoneum, and retroperitoneum [10].

Pontes and Oldford reported that breast cancer metastasizes to the bladder through retroperitoneal involvement [6]. It could be explained by tumor embolus that does not seed in the lung but passes through pulmonary circulation and reaches the target organ and soil there, causing a metastasis $[6,11]$. Some suggested that when invasive lobular carcinoma loses e-cadherin, cell-cell adhesion is lost increasing the number of metastases [12].

The majority of bladder metastases is part of widespread disease [2]. Clinical presentation can range from asymptomatic presentation, as it was the case in our patient, to gross hematuria, obstructive uropathy, and renal failure [2, 3, 5, 11-13].

Bladder metastasis from breast cancer may arise late, sometimes even 30 years after the diagnosis of the primary tumor $[2,13,14]$. In our case, bladder metastasis was diagnosed 13 years later after treatment of initial breast cancer.

Radiologic exploration for patients suspected to have bladder metastases consists bladder ultrasound, computed tomography scan, or magnetic resonance imaging
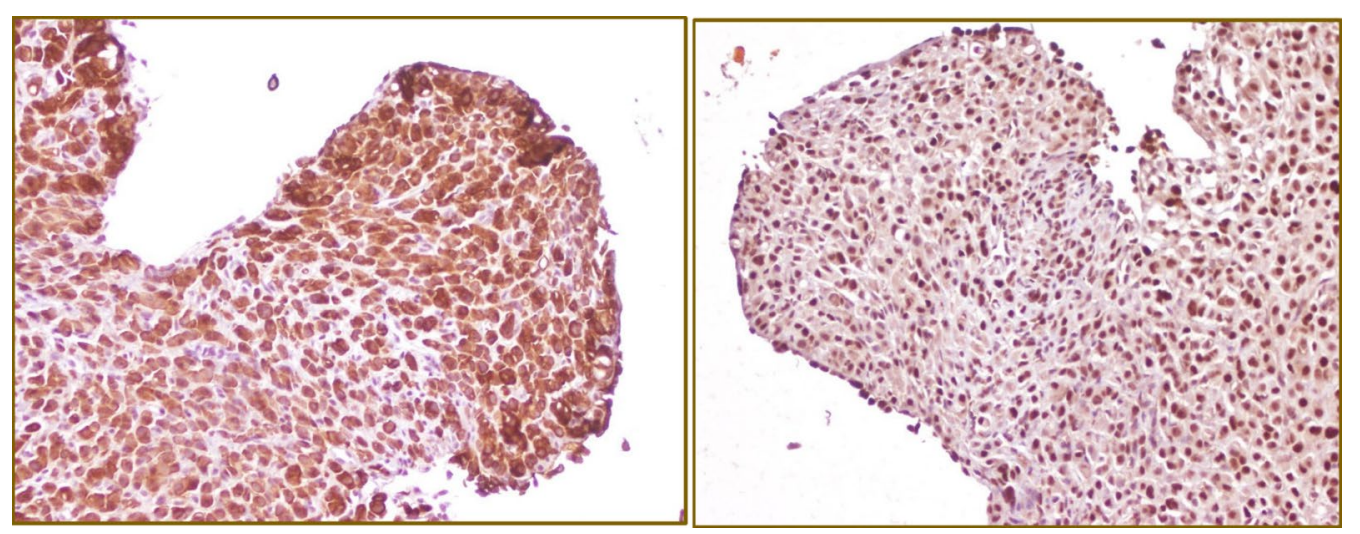

Fig. 2 Immunohistochemically, the tumor cells were positive for CK-7 (a) and GATA3 (b) (× 200) 
of the pelvis $[2,12]$. Typically, bladder wall thickening is seen with or without hydronephrosis and hydroureter [12] as was found in our patient.

When the lesion is detected, we follow-up with histological proof, obtained either by cystoscopy and cold-cup biopsy or transurethral resection $[2,8,12,14]$.

Histology and immunohistochemistry, by testing for estrogen and progesterone receptors as well as human epidermal growth factor receptor 2 (Her2), are essential to rule out primary bladder cancer. Some authors have however noted discordance in hormonal status in primary and metastatic sites $[8,12,15]$. When this situation occurs, the GCDFP-15 (gross cystic disease fluid protein 15) marker is used to make the difference between primary and secondary bladder cancer [13].

Therapies include local resection of the bladder tumor during cystoscopy, palliative radiotherapy, and systemic therapy $[2,8,12]$.

Systemic therapy includes chemotherapy and hormonal treatment. It was observed that positive receptor tumors respond better to hormonal therapy than the negative receptor tumors $[8,16]$.

Percutaneous nephrostomy can also be undertaken to normalize renal function, thus making the patient suitable for further administration of systemic chemotherapy [17].

Patients with bladder metastases from breast cancer usually have poor prognosis, with a survival between 1 month and 2 years $[2,8]$, although there are reports of survival for more than 5 years [18-21]. In the case of our patient, she died one year after bladder metastasis diagnosis.

This is likely due to the fact that in the vast majority of bladder metastases cases, metastases to other organs were also present [8].

\section{Conclusion}

Bladder metastasis from breast cancer is scarce [21]. In view of the frequency of breast cancer, doctors should always consider unusual metastatic sites such as the bladder. Most bladder metastases occur in invasive lobular cancer [2].

It is important to conduct a radiological exploration and to provide a histological proof, preferably by performing transurethral resection.

Chemotherapy and hormonal therapy are the cornerstone of management of this type of metastasis. Radiotherapy is usually reserved to control bleeding. The prognosis of bladder metastases is poor unless it represents the only metastatic site $[2,8]$.
Abbreviations

ER: Estrogen; PR: Progestrone.

\section{Acknowledgements}

We thank the participants in this case study as well as the subject's family for providing their consent for publication.

\section{Authors' contributions}

All of the authors (A.H., R.A., N.M., A.M., K.M., N.B., C.N.) have approved the contents of this paper and have agreed to the submission policies. Each named author has substantially contributed to conducting the underlying research and drafting this manuscript. All authors read and approved the final manuscript.

\section{Funding}

No funding.

Availability of data and materials

Not applicable.

\section{Declarations}

Ethics approval and consent to participate

The article is in accordance with the ethical standards of the institution. The treatment was discussed with patient who consented to participate.

\section{Consent for publication}

The subject's family has given their written informed consent to publish their case (including publication of images). No Information revealed the subject's identity.

\section{Competing interests}

The authors declare that they have no competing interests.

\section{Author details}

${ }^{1}$ Radiotherapy Unit, Salah Azaiez Institute of Cancer, Boulevard du 9 avril 1938 Bab Saâdoun, 1007 Tunis, Tunisia. ${ }^{2}$ Department of Pathology, Salah Azaiz Institute, Tunis, Tunisia. ${ }^{3}$ Laboratory Microorganismes and Active Biomolecules, Sciences Faculty of Tunis, Université de Tunis El Manar, Tunis, Tunisia. ${ }^{4}$ Medical Oncology Unit, Jendouba Regional Hospital, Jendouba, Tunisia.

Received: 20 April 2021 Accepted: 10 Auqust 2021

Published online: 23 August 2021

References

1. Cherif A, Dhaouadi S, Osman M, Hsairi M (2019) Breast Cancer burden in Tunisia: situation in 2017 and projections by 2030. Eur J Public Health 29(Supplement_4):ckz186.232. https://doi.org/10.1093/eurpub/ckz186. 232

2. Karjol U et al (2020) Bladder metastasis from breast cancer: a systematic review. Cureus 12(3):e7408-e7408. https://doi.org/10.7759/cureus.7408

3. Jordan LA, Green L (2018) Late breast cancer metastasis to the urinary bladder presenting with bilateral hydronephrosis. Radiol Case Rep 13(6):1238-1241. https://doi.org/10.1016/j.radcr.2018.08.029

4. DeSantis C et al (2014) Breast cancer statistics, 2013. CA: Cancer J Clin 64(1):52-62. https://doi.org/10.3322/caac.21203

5. Ramsey J, Beckman EN, Christian Winters J (2008) Breast cancer metastatic to the urinary bladder. Ochsner J 8(4):208-212

6. Karaosmanoglu AD, Onur MR, Karcaaltincaba M, Akata D, Ozmen MN (2018) Secondary tumors of the urinary system: an imaging conundrum. Korean J Radiol 19(4):742-751. https://doi.org/10.3348/kjr.2018.19.4.742

7. Pontes JE, Oldford JR (1970) Metastatic breast carcinoma to the bladder. J Urol 104(6):839-842. https://doi.org/10.1016/s0022-5347(17)61848-2

8. Sanguedolce $F$ et al (2018) Bladder metastases from breast cancer: managing the unexpected. A systematic review. Urol Int 101(2):125-131. https://doi.org/10.1159/000481576 
9. Yoneyama K, Nakagawa M, Hara A (2018) Bladder metastasis from primary breast cancer: a case report. Surg Case Rep 4(1):73. https://doi.org/ 10.1186/s40792-018-0484-6

10. Borst MJ, Ingold JA (1993) Metastatic patterns of invasive lobular versus invasive ductal carcinoma of the breast. Surgery 114(4):637-641 (discussion 641-642)

11. Goldstein AG (1967) Metastatic carcinoma to the bladder. J Urol 98(2):209-215. https://doi.org/10.1016/s0022-5347(17)62857-x

12. Gitau SN, Njau A, Mwanzi S (2019) Urinary bladder metastasis from breast cancer: a rare cause of hematuria. BJR Case Rep 6(1):20190048. https:// doi.org/10.1259/bjrcr.20190048

13. Cormio L, Sanguedolce F, Di Fino G, Massenio P, Liuzzi G, Ruocco N, Bufo P, Carrieri G (2014) Asymptomatic bladder metastasis from breast cancer. Case Rep Urol 2014:672591. https://doi.org/10.1155/2014/672591

14. Junejo N, Hussain TA, Hathal NA (2018) Unusual pattern of breast carcinoma metastasis to the urinary bladder: case report and review of literature. Saudi Surg J 6(2):66-68

15. Feldman PA et al (2002) Metastatic breast cancer to the bladder: a diagnostic challenge and review of the literature. Urology 59(1):138. https:// doi.org/10.1016/s0090-4295(01)01489-3
16. Lin W-C, Chen J-H (2007) Urinary bladder metastasis from breast cancer with heterogeneic expression of estrogen and progesterone receptors. J Clin Oncol 25(27):4308-4310. https://doi.org/10.1200/JCO.2007.12.9379

17. Shah KG, Modi PR, Rizvi J (2011) Breast carcinoma metastasizing to the urinary bladder and retroperitoneum presenting as acute renal failure. Indian J Urol 27(1):135-136. https://doi.org/10.4103/0970-1591.78421

18. Silverstein LI et al (1987) Breast Carcinoma Metastatic to Bladder. Urology 29(5):544-547. https://doi.org/10.1016/0090-4295(87)90048-3

19. Wong MH, Yiu MK, Ho KL (2013) Metastatic Carcinoma of Breast in the Urinary Bladder. Hong Kong Med J 19(5):455-457. https://doi.org/10. 12809/hkmj133768

20. Ryan PD et al (2006) Case Records of the Massachusetts General Hospital. Case 6-2006. A 71-year-old woman with urinary incontinence and a mass in the bladder. New Engl J Med 354(8):850-856. https://doi.org/10.1056/ NEJMcpc059042

21. Bates AW, Baithun SI (2000) Secondary neoplasms of the bladder are histological mimics of nontransitionalcell primarytumours: clinicopathological and histological features of 282 cases. Histopathology 36(1):32-40. https://doi.org/10.1046/j.1365-2559.2000.00797.x

\section{Submit your manuscript to a SpringerOpen ${ }^{\odot}$ journal and benefit from:}

- Convenient online submission

- Rigorous peer review

- Open access: articles freely available online

- High visibility within the field

- Retaining the copyright to your article

Submit your next manuscript at $\gg$ springeropen.com 